\title{
Editorial
}

\section{Psicologia da Saúde: Uma Nova Área de Publicação na Revista Psicologia: Reflexão e Crítica}

É com grande satisfação que estamos anunciando mudanças na política editorial da Revista Psicologia: Reflexão e Crítica/Psychology. Buscando contemplar de forma mais adequada possível um maior número de trabalhos, mantendo ainda áreas específicas e que abordem diversos temas que remetem ao rico universo das "psicologias" atuais, estamos ampliando nossas áreas de publicação. O processo de seleção dos textos continua mantendo a tradição da nossa revista, que publica textos originais, e que busca difundir o conhecimento psicológico em suas mais diversas facetas. No entanto, considerando o crescimento e diversificação da produção da psicologia nos diversos contextos nacionais e internacionais, decidimos incluir a área da Psicologia da Saúde. Essa definição tem por objetivo sistematizar melhor os trabalhos recebidos e, a partir da contribuição de um editor específico na área, qualificar melhor o processo de seleção e avaliação dos manuscritos submetidos.

Tal definição é resultado da análise dos artigos que vêm sendo submetidos e publicados na nossa revista, que de alguma forma se enquadram na área de Psicologia da Saúde. Embora seja relativamente nova, pois a Psicologia da Saúde começou com um grupo de trabalho em 1970, na American Psychological Association (APA), e somente em 1978 foi criada a divisão 38, chamada Health Psychology, pode ser observado um importante crescimento nas práticas profissionais e pesquisas nacionais e internacionais nessa área. As publicações em Psicologia da Saúde têm aumentado quantitativa e qualitativamente, tanto no formato de artigos como de livros, gerando material importante para a divulgação do conhecimento e a formação de novos profissionais que ingressam na área. Também é possível constatar a realização de congressos científicos e eventos, criação de grupos de trabalho, organizações e sociedades, assim como o crescimento e valorização de periódicos específicos em Psicologia da Saúde, tanto no Brasil como no exterior.

A partir dessa mudança na política editorial, também decidimos reformular a descrição das áreas de submissão, para que nossos colaboradores possam ter mais clara a abrangência de cada uma delas. Dessa forma, a Revista Psicologia: Reflexão e Crítica/Psychology passa a publicar trabalhos originais nas áreas de Processos Psicológicos Básicos, Avaliação Psicológica, Psicologia do Desenvolvimento e Psicologia da Saúde, nas seguintes categorias: relatos de pesquisa, artigos teóricos ou de revisão sistemática, comunicações breves e resenhas. Os autores, ao encaminharem seus artigos, deverão enviar carta ao editor, justificando sua escolha e destacando as contribuições e a relevância do trabalho para a área pretendida. Além disso, quando pertinente, os autores também deverão incluir uma declaração de que os procedimentos éticos foram seguidos de acordo com a legislação vigente no(s) país(es) em que foi realizada a pesquisa, incluindo cópia de aprovação do Comitê de Ética, quando se tratar de artigo empírico. A nova descrição das áreas, a partir da contribuição dos editores associados em sua reformulação, passa a ser a seguinte:

PROCESSOS PSICOLÓGICOS BÁSICOS: Nessa área são incluídos estudos sobre processos como sensação, atenção, percepção, aprendizagem, linguagem, memória, motivação e emoção. Para efeito desta tematização da revista, estudos que investiguem funções cognitivas complexas, como: linguagem, raciocínio, resolução de problemas, tomada de decisão, funções executivas também podem ser incluídos. Geralmente, são aceitos estudos que empregam os métodos experimental e quase experimental, abordando interfaces com as áreas de neurociências, neuropsicologia, neurologia, psicologia cognitiva, psicobiologia, psicofarmacologia, e análise experimental do comportamento. São aceitos estudos com populações clínicas e não clínicas, em contextos experimentais ou naturais, em ambientes formais e não formais, cibernéticos e de realidade virtual.

AVALIAÇÃO PSICOLÓGICA: Esta seção está focada no avanço da ciência, da prática e da ética da avaliação psicológica nos seus diversos contextos, incluindo trabalhos com temas relacionados à mensuração psicológica e psicometria, adaptação, desenvolvimento, validação ou normatização de instrumentos, uso de instrumentos para fins de avaliação psicológica, psicodiagnóstico, avaliação de intervenções ou de programas e estudos de caso envolvendo o uso de instrumentos. Artigos centrados na avaliação do funcionamento cognitivo e neuropsicológico, personalidade e psicopatologia, bem como avaliação empírica de fenômenos clinicamente relevantes, tais como comportamentos disfuncionais, características e diagnósticos de personalidade, também poderão ser submetidos. Além disso, poderão fazer parte dessa seção trabalhos que envolvam questões éticas ou técnicas envolvendo Avaliação Psicológica.

PSICOLOGIA DO DESENVOLVIMENTO: Para publicar nessa seção os estudos devem apresentar uma abordagem evolutiva, não sendo suficiente ter sido realizado com crianças, adolescentes, adultos ou idosos para ter potencial para ser publicado nessa área. O estudo do desenvolvimento em psicologia consiste na investigação de mudanças ao 
longo do tempo no fenômeno de interesse. Uma abordagem evolutiva requer pesquisa no período de tempo durante o qual as mudanças enfocadas ocorrem, sejam em um período relativamente curto de tempo (mudanças microgenéticas) sejam em um período relativamente longo de tempo (mudanças ontogenéticas). Para a compreensão dos processos envolvidos nas mudanças, estudos longitudinais são essenciais; também pesquisas transversais possibilitam mostrar se as diferenças previstas (por exemplo, em sentimentos, valores, cognição ou socialização) são encontradas em amostras que incluem as idades relevantes para o tópico que está sendo estudado; e, ainda, alguns tipos de método retrospectivo também possibilitam acessar mudanças relacionadas com a idade. Mudanças microgenéticas referem-se a mudanças que ocorrem em um período relativamente curto de tempo, por exemplo, da heterorregulação para a autorregulação em tarefas de resolução de problemas por crianças; mudanças durante a aprendizagem de habilidades ou tarefas específicas. Mudanças ontogenéticas geralmente ocorrem durante períodos mais longos de tempo, por exemplo, quando se investiga mudanças na forma de pensamento, relações sociais ou respostas emocionais na passagem dos jovens pela puberdade ou quando atingem o pensamento formal, ou ainda, a transição para a parentalidade, os efeitos da obtenção de um novo emprego, da aposentadoria ou da viuvez na vida de adultos. A origem da mudança pode ser psicobiológica (por exemplo, aumento da mielinização do córtex cerebral; passagem pela puberdade; variação nos níveis de motivação ou persistência, etc.), ambiental (por exemplo, os efeitos do fumo no peso dos bebês ao nascer; a exposição à intoxicação do ar ou da água), social (necessidade de aprender uma nova habilidade em casa, na escola ou no trabalho; mudança de escola; processo de divórcio; saída dos filhos de casa, etc.), cultural (por exemplo, mudança de país; casamento com pessoa de um grupo étnico diferente do seu próprio), ou uma combinação de duas ou mais destas.

PSICOLOGIA DA SAÚDE: Nessa área são incluídos estudos sobre as relações empíricas entre os fatores psicológicos, o comportamento e a saúde. A seção Psicologia da Saúde publica artigos acadêmicos originais que abordem temas como: Fatores contextuais e do comportamento que podem contribuir para o adoecimento ou a prevenção das doenças; avaliação das abordagens em saúde; comportamentos de proteção ou de risco para a saúde; estratégias de promoção e educação para a saúde; psicologia pediátrica; psico-oncologia; envelhecimento saudável; avaliação e divulgação de intervenções em psicologia da saúde baseadas em evidências que têm como alvo tanto o indivíduo, a família, o grupo, ou comunidade; etnia, classe social, gênero e orientação sexual na saúde; disparidades em saúde; aplicações dos resultados de pesquisas para as políticas relacionadas com a saúde; questões profissionais em psicologia da saúde, incluindo a formação e supervisão.

Embora, em algumas situações, possa haver uma aparente sobreposição das áreas, os autores deverão observar o principal objetivo do trabalho a ser submetido para decidir a área de submissão. Como exemplo, um artigo que enfoque o desenvolvimento de instrumento para avaliação de variáveis relacionadas à saúde poderá ser submetido à área de Avaliação Psicológica, por enfocar com maior ênfase os aspectos psicométricos do instrumento e seu desenvolvimento; enquanto que um artigo que enfoque a adesão ao tratamento, ao longo da infância e adolescência, poderá ser enquadrado na área de Psicologia do Desenvolvimento, se a discussão for centrada numa abordagem evolutiva, observando mais os processos ontogenéticos presentes nas mudanças ocorridas ao longo do tempo do que os processos de saúde envolvidos. Nossa equipe de editores associados avaliará essas questões e direcionará os trabalhos para as áreas específicas.

Considerando essas novas definições, também ocorreram mudanças na distribuição dos nossos editores associados, configurando-se nosso corpo editorial da seguinte forma: Professores Lia Beatriz de Lucca Freitas (UFRGS) e Jonathan Richard Henry Tudge (University of North Carolina at Greensboro) na área de Psicologia do Desenvolvimento; Professor Eduardo Augusto Remor (Universidade Autônoma de Madrid) na área de Psicologia da Saúde; Professor Maycoln Teodoro (UFMG) na área de Avaliação Psicológica; e Profa. Rosa Maria Martins de Almeida (UFRGS), na área de Processos Básicos.

Com essa nova proposição, desejamos continuar recebendo colaborações significativas dos autores e reafirmar nossa presença no cenário das publicações nacionais e internacionais em psicologia. Temos o máximo interesse em garantir a credibilidade de nosso trabalho e precisamos continuar contando com o apoio, ética e seriedade de todos: equipe editorial, autores e leitores.

Nosso muito obrigado a todos e boa leitura!

Débora Dalbosco Dell’Aglio Editora 